\title{
STANDARDS OF BIRTH WEIGHT ACCORDING TO GESTATIONAL AGE IN THE NORTHWESTERN REGIONS OF UKRAINE
}

\author{
O. Rodych ${ }^{1}$, Y. Korzhynskyy ${ }^{1}$ and T. Gutor ${ }^{2}$ \\ ${ }^{1}$ Department of Pediatrics and Neonatology, Faculty of Postgraduate Education, \\ Danylo Halytsky Lviv National Medical University \\ ${ }^{2}$ Department of Organization and Management of Health, Faculty of Postgraduate Education, \\ Danylo Halytsky Lviv National Medical University
}

\begin{abstract}
Summary. An analysis of the neonatal registry for 2001-2010 years in Rivne and Volyn regions of Ukraine as well as 2006-2011 years of Khmelnytsky region was carried out. General information was available about body weight of 366607 newborns, among which 188687 were boys and 177920 girls. Based on the analysis we developed local standards of birth body weight in relation to gestational age separately for boys and girls. Procedure for processing local standards met international standards that have been developed by the WHO. Availability of processed local standards depending on gestational age will enable neonatologists, pediatricians and researchers to clearly identify anomalies in the health of newborns in the northwestern regions of Ukraine. Therefore, identification of newborns with low or high birth weight will enable adequate and timely steps to improve their health.
\end{abstract}

Key words: standards, birth weight, gestational age, the northwestern region of Ukraine

\section{INTRODUCTION}

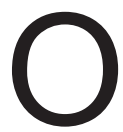

ne of the objective markers of the health status of newborns is the level of physical development. Anthropometric rates are considered as integral features of fetal growth [11].

Assessment of physical development of the child population is carried out by comparing individual anthropometric rates with standards. In turn, standard rates of physical development have their features and patterns defined by a complex set of local conditions: climatic and geographical, social and economic, ecological, etc. Therefore, average rates of physical development common to all regions of the country cannot be sufficiently objective. They are influenced by local features and conditions of the region (J. M. Nechytaylo, 1999; R. V. Bohatyrova et al., 2000).

Creating standards of children physical development and their periodic renovation should be considered as a prerequisite for monitoring changes in the child organism, individual pre- 
diction of health, carrying out medical and organizational, social and hygienic measures of prevention (A. L. Reznikova et al., 2002).

Early identification of infants with deviation in physical development according to regional standards and their individual assessment enable timely creation of adequate conditions for their nursing, prevent the occurrence of a number of emergency conditions in postnatal ontogenesis (A.L. Reznikova et al., 2002).

\section{OBJECTIVE}

Create local standards of the birth weight according to gestational age for boys and girls born in the northwestern regions of Ukraine.

\section{MATERIALS AND METHODS}

The analysis of the neonatal registry was performed for the period 2001-2011 in Rivne and Volyn regions of Ukraine as well as for the period 2006-2011 in Khmelnytsky region. Body mass indexes of infants, their gestational age, sex, presence or absence of birth defects, diseases of the mother were noted in the registry. All infants with birth weight $<1000 \mathrm{~g}$ and/or gestational age $<28$ weeks were included in the registry since 2004 . Thus, data about 388,054 infants (200 561 boys and 187493 girls) with gestational age 25-44 weeks who were born during 2001-2011 years in Volyn, Rivne and Khmelnitsky regions were included in the study. Exclusion criteria were infants with unknown sex (1.74\%) and stillbirths.

In drawing up centile tables and charts it was not taken into account the weight of children with birth defects - 14, $918(3.84 \%)$ cases, and infants born from multiple pregnancies (without birth defects) $-6,323(1.63 \%)$ cases.

Overall, selected information included body weight of 366,607 newborns, among whom were 188,687 boys and 177,920 girls with gestational age from 27 to 43 weeks (Table 1).

Table 1. Distribution of infants in Volyn, Rivne and Khmelnitsky regions by gestational age and sex

\begin{tabular}{|l|l|l|l|}
\hline Gestational age, weeks & Boys & Girls & Both sexes \\
\hline 27 & 101 & 88 & 189 \\
\hline 28 & 104 & 104 & 208 \\
\hline 29 & 136 & 102 & 238 \\
\hline 30 & 283 & 229 & 512 \\
\hline 31 & 252 & 233 & 485 \\
\hline 32 & 470 & 421 & 891 \\
\hline 33 & 486 & 407 & 893 \\
\hline 34 & 818 & 721 & 1,539 \\
\hline 35 & 1,105 & 1,013 & 2,118 \\
\hline 36 & 1,989 & 1,938 & 3,927 \\
\hline 37 & 6,639 & 5,940 & 12,579 \\
\hline 38 & 19,228 & 17,939 & 37,167 \\
\hline 39 & 40,110 & 38,127 & 78,237 \\
\hline 40 & 93,595 & 87,938 & 181,533 \\
\hline 41 & 18,513 & 18,207 & 36,720 \\
\hline 42 & 4,501 & 4,237 & 8,738 \\
\hline 43 & 357 & 276 & 633 \\
\hline Total & 188,687 & 177,920 & 366,607 \\
\hline
\end{tabular}


For processing the raw data, database in the program "Exel" was developed and statistical programs were prepared which were used in a standardized way in all parts of the study. System of control after received data included methods of internal and central validation of data collection for further promptly identifying any errors. Each research site was responsible for the collection, administration, validation and refinement of the data and creating master database locally. Each month data from research sites forwarded to form the united main file and the wider checking. About all detected errors it was reported to the research sites for their on-site correction. Meticulous execution of this algorithm led to the high quality of the received data.

Measurement of birth weight was carried out in the first day after birth. In all research sites were used the same equipment. Body weight was measured using medical electronic baby balance. Gestational age was assessed according to clinical examination at childbirth and date of the first day of the last menstruation.

In the sample were included live births of singleton pregnancies. The exclusion criteria from the study were stillborn children, persons of unknown sex, newborns from multiple pregnancies, newborns with congenital malformations or dimorphism, and newborns in gestational age of 25, 26 and 44 weeks due to lack of their number.

Constructing growth curves included determining the type of distribution and an optimal smoothing technique. Therefore, we have determined that the obtained raw data most relevant to Box-Cox distribution (Box-Cox power exponential) [1], and smoothing curves best carried out by way of a polynomial smoothing according to polynomial of 3rd degree [2].

The process of selecting the best model in constructing growth curves included, first, the choice of the best model within a class of models and, secondly, the best model among different classes of models. To select the best model within a class of models we used Akaike criteria and their generalized version [3]. In order to determine the degree of polynomial we used worm plots [4] and Q-tests [5]. However, when choosing the best model we have worked out the differences between empirical and smoothed percentiles and calculations of the expected particle of children who find themselves outside the standard parameters. In general, we choose a sequence of actions to determine the type of distribution and select the optimal smoothing techniques to meet international standards that have been developed by $\mathrm{WHO}[6]$.

\section{RESULTS}

During the performance, we calculated the standard body weight of boys at birth according to gestational age in the northwestern regions of Ukraine, as shown in table 2 and figure 1. These data allow us to easily determine whether birth weight of individual child, depending on gestational age and sex, is normal or vice versa - too high or low for gestational age. Achieved data allows comparing the weight of a newborn with standard parameters.

Due to received data it is possible to determine whether weight of the newborn boy meets local standard rates in the northwestern region of Ukraine or not. Through detailed calculations with definition of 2.5 th, 5th, 10th, 25th, 75th, 90th, 95th, 97.5th centile and median, there is an opportunity to classify newborns in one of the following groups: medium, higher/lower than medium; high or low; as well as very high or very low birth weight, according to the algorithm shown in table 3 [7]. This methodology can be used for children born full-term, preterm and post-term. 
Table 2. Standard body weight of newborn boys according to gestational age in the northwestern regions of Ukraine

\begin{tabular}{|c|c|c|c|c|c|c|c|c|c|}
\hline \multirow{2}{*}{$\begin{array}{l}\text { Gestational age, } \\
\text { weeks }\end{array}$} & \multicolumn{9}{|c|}{ Centile, gram } \\
\hline & 2,5 & 5 & 10 & 25 & 50 & 75 & 90 & 95 & 97,5 \\
\hline 27 & 750 & 790 & 850 & 940 & 1030 & 1180 & 1340 & 1590 & 2070 \\
\hline 28 & 810 & 850 & 930 & 1050 & 1180 & 1320 & 1500 & 1730 & 2200 \\
\hline 29 & 890 & 950 & 1050 & 1190 & 1320 & 1500 & 1680 & 1910 & 2320 \\
\hline 30 & 1010 & 1090 & 1200 & 1340 & 1500 & 1680 & 1890 & 2100 & 2490 \\
\hline 31 & 1160 & 1240 & 1350 & 1530 & 1690 & 1890 & 2090 & 2310 & 2670 \\
\hline 32 & 1310 & 1400 & 1530 & 1710 & 1900 & 2100 & 2310 & 2530 & 2860 \\
\hline 33 & 1490 & 1590 & 1700 & 1910 & 2110 & 2320 & 2550 & 2770 & 3060 \\
\hline 34 & 1660 & 1790 & 1900 & 2110 & 2320 & 2580 & 2790 & 3000 & 3250 \\
\hline 35 & 1850 & 1970 & 2090 & 2320 & 2530 & 2800 & 3030 & 3220 & 3450 \\
\hline 36 & 2030 & 2170 & 2280 & 2520 & 2760 & 3030 & 3260 & 3460 & 3660 \\
\hline 37 & 2210 & 2340 & 2470 & 2720 & 2970 & 3240 & 3490 & 3680 & 3830 \\
\hline 38 & 2380 & 2510 & 2660 & 2900 & 3160 & 3450 & 3710 & 3890 & 4030 \\
\hline 39 & 2530 & 2680 & 2810 & 3080 & 3340 & 3630 & 3900 & 4080 & 4210 \\
\hline 40 & 2670 & 2810 & 2980 & 3220 & 3500 & 3800 & 4090 & 4250 & 4370 \\
\hline 41 & 2780 & 2910 & 3090 & 3340 & 3640 & 3930 & 4230 & 4390 & 4510 \\
\hline 42 & 2870 & 3000 & 3200 & 3450 & 3750 & 4030 & 4350 & 4510 & 4630 \\
\hline 43 & 2930 & 3040 & 3280 & 4010 & 3830 & 4100 & 4440 & 4600 & 4730 \\
\hline
\end{tabular}

Table 3. Proposed assessment scale of newborn weight with method of centile standards

\begin{tabular}{|l|l|}
\hline Body weight assessment & Centile standards \\
\hline Very high & $>97,5$ centiles \\
\hline High & $90-97,5$ centiles \\
\hline Higher than medium & $75-90$ centles \\
\hline Medium & $25-75$ centiles \\
\hline Lower than medium & $25-10$ centiles \\
\hline Low & $10-2,5$ centiles \\
\hline Very low & $<2,5$ centiles \\
\hline
\end{tabular}

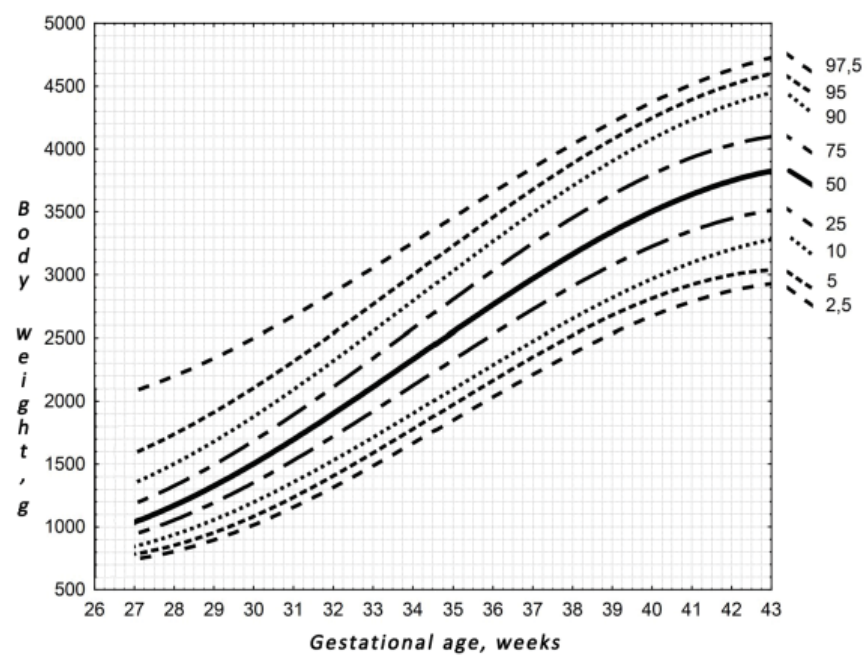

Fig. 1. Standard body weight of newborn boys according to gestational age in the northwestern regions of Ukraine 
It was established that the median birth weight of boys ranging from $1030 \mathrm{~g}$ (at 27 weeks of gestation) to $3830 \mathrm{~g}$ (at 43 weeks of gestation). However, full-term newborn boys had median body weight in the range from $2970 \mathrm{~g}$ (37 weeks) to $3750 \mathrm{~g}$ (42 weeks).

Very low body weight in boys was stated when analyzed index was lower than $750 \mathrm{~g}$ at 27 weeks of gestation and less than $2930 \mathrm{~g}$ at 43 weeks of gestation.

Very high body weight in newborn boys was diagnosed in cases where the birth weight of $2070 \mathrm{~g}$ prevails at 27 weeks of gestation and $4730 \mathrm{~g}$ at 43 weeks of gestation.

Similarly, having the data for boys, we calculated the standard body weight of girls at birth according to gestational age in the northwestern regions of Ukraine, as shown in table 4 and in fig. 2.

Table 4. Standard body weight of newborn girls according to gestational age in the northwestern regions of Ukraine

\begin{tabular}{|c|c|c|c|c|c|c|c|c|c|}
\hline \multirow{2}{*}{$\begin{array}{c}\text { Gestational age, } \\
\text { weeks }\end{array}$} & \multicolumn{9}{|c|}{ Centile, gram } \\
\cline { 2 - 10 } & $\mathbf{2 , 5}$ & $\mathbf{5}$ & $\mathbf{1 0}$ & $\mathbf{2 5}$ & $\mathbf{5 0}$ & $\mathbf{7 5}$ & $\mathbf{9 0}$ & $\mathbf{9 5}$ & $\mathbf{9 7 , 5}$ \\
\hline $\mathbf{2 7}$ & 610 & 650 & 750 & 870 & 970 & 1120 & 1330 & 1570 & 1800 \\
\hline $\mathbf{2 8}$ & 630 & 690 & 830 & 980 & 1100 & 1280 & 1500 & 1830 & 2090 \\
\hline $\mathbf{2 9}$ & 700 & 800 & 940 & 1110 & 1260 & 1440 & 1680 & 2050 & 2330 \\
\hline 30 & 850 & 940 & 1090 & 1280 & 1440 & 1630 & 1890 & 2280 & 2550 \\
\hline 31 & 1010 & 1110 & 1280 & 1470 & 1620 & 1830 & 2080 & 2470 & 2740 \\
\hline 32 & 1190 & 1320 & 1470 & 1640 & 1830 & 2030 & 2290 & 2630 & 2900 \\
\hline 33 & 1410 & 1530 & 1670 & 1850 & 2040 & 2240 & 2500 & 2810 & 3060 \\
\hline 34 & 1630 & 1750 & 1890 & 2040 & 2260 & 2470 & 2700 & 2980 & 3190 \\
\hline 35 & 1850 & 1980 & 2100 & 2250 & 2470 & 2690 & 2920 & 3130 & 3330 \\
\hline 36 & 2050 & 2180 & 2310 & 2440 & 2670 & 2900 & 3120 & 3300 & 3480 \\
\hline 37 & 2230 & 2370 & 2490 & 2640 & 2880 & 3110 & 3330 & 3460 & 3610 \\
\hline 38 & 2390 & 2520 & 2640 & 2810 & 3060 & 3310 & 3520 & 3630 & 3790 \\
\hline 39 & 2510 & 2640 & 2770 & 2970 & 3200 & 3490 & 3710 & 3820 & 3970 \\
\hline 40 & 2570 & 2700 & 2850 & 3090 & 3360 & 3640 & 3900 & 4010 & 4160 \\
\hline 41 & 2580 & 2710 & 2890 & 3190 & 3470 & 3790 & 4060 & 4220 & 4420 \\
\hline 42 & 2530 & 2660 & 2860 & 3270 & 3530 & 3900 & 4220 & 4460 & 4700 \\
\hline 43 & 2400 & 2540 & 2780 & 3300 & 3570 & 3980 & 4380 & 4720 & 5020 \\
\hline
\end{tabular}

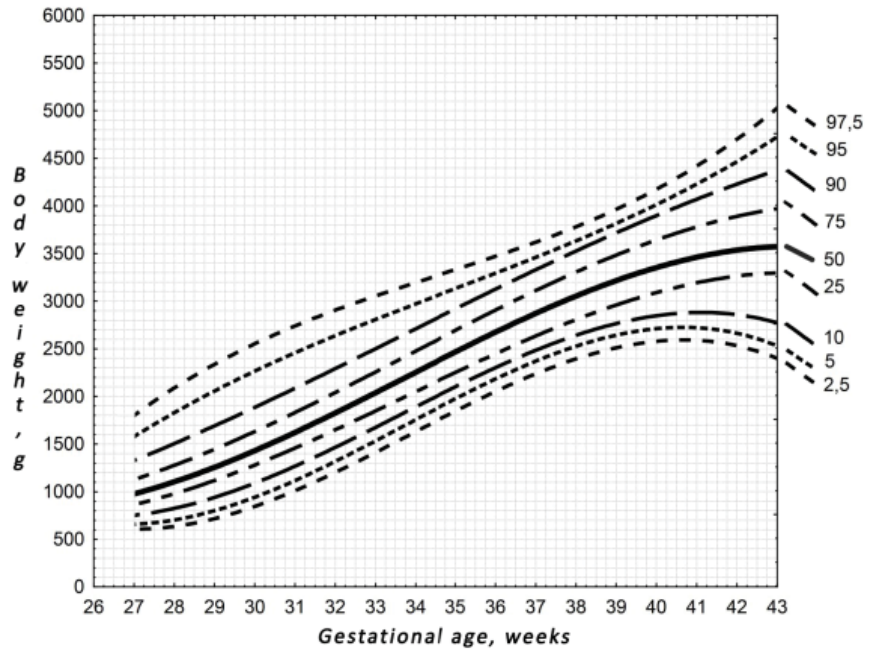

Fig. 2. Standard body weight of newborn girls according to gestational age in the northwestern regions of Ukraine 
It was found that almost all indicators of body mass in girls were lower than the same measures in boys, with the exception of some indicators at 95 and 97.5 percentile. It was determined that the median birth weight of girls ranging from $970 \mathrm{~g}$ (at 27 weeks of gestation) to $3570 \mathrm{~g}$ (at 43 weeks of gestation). However, full-term newborn girls had median body weight ranging from $2880 \mathrm{~g}$ (37 weeks) to $3530 \mathrm{~g}$ (42 weeks).

Very low weight of girls was stated when analyzed index was lower than $610 \mathrm{~g}$ at 27 weeks of gestation and less than $2400 \mathrm{~g}$ at 43 weeks of gestation.

Very high body weight in newborn girls was diagnosed in cases where the birth weight at 27 weeks of gestation was greater than $1800 \mathrm{~g}$ or greater than $5020 \mathrm{~g}$ at 43 weeks of gestation.

Table 5. Standardized median (50th centile) of body weight of newborn boys in the northwestern regions of Ukraine in comparison with other studies

\begin{tabular}{|c|c|c|c|c|c|c|c|c|c|}
\hline \multirow{2}{*}{$\begin{array}{c}\text { Gestational age, } \\
\text { weeks }\end{array}$} & \multirow{2}{*}{$\begin{array}{c}\text { Our study } \\
\text { BW }\end{array}$} & \multicolumn{2}{|c|}{$\begin{array}{c}\text { Denver, } \\
\text { Colorado,USA, } 1961\end{array}$} & \multicolumn{2}{|c|}{$\begin{array}{l}\text { Hamilton, Ontario, } \\
\text { Canada, } 1984\end{array}$} & \multicolumn{2}{|c|}{ Malta, 2009} & \multicolumn{2}{|c|}{$\begin{array}{l}\text { INTERGROWTH-21st } \\
\text { Project, } 2014\end{array}$} \\
\hline & & BW & $\%$ & BW & $\%$ & BW & $\%$ & BW & $\%$ \\
\hline 23 & n.d. & n.d. & - & n.d. & - & 472 & - & n.d. & - \\
\hline 24 & n.d. & 830 & - & n.d. & - & 614 & - & n.d. & - \\
\hline 25 & n.d. & 880 & - & n.d. & - & 757 & - & n.d. & - \\
\hline 26 & n.d. & 965 & - & n.d. & - & 903 & - & n.d. & - \\
\hline 27 & 1030 & 1080 & $+4,85$ & n.d. & - & 1056 & $+2,52$ & n.d. & - \\
\hline 28 & 1180 & 1205 & $+2,12$ & n.d. & - & 1218 & $+3,22$ & n.d. & - \\
\hline 29 & 1320 & 1330 & $+0,76$ & n.d. & - & 1390 & $+5,30$ & n.d. & - \\
\hline 30 & 1500 & 1465 & $-2,33$ & n.d. & - & 1572 & $+4,80$ & n.d. & - \\
\hline 31 & 1690 & 1600 & $-5,33$ & n.d. & - & 1764 & $+4,38$ & n.d. & - \\
\hline 32 & 1900 & 1760 & $-7,37$ & n.d. & - & 1964 & $+3,37$ & n.d. & - \\
\hline 33 & 2110 & 1970 & $-6,64$ & n.d. & - & 2171 & $+2,89$ & 1950 & $-7,58$ \\
\hline 34 & 2320 & 2220 & $-4,31$ & n.d. & - & 2381 & $+2,63$ & 2220 & $-4,31$ \\
\hline 35 & 2530 & 2520 & $-0,40$ & n.d. & - & 2590 & $+2,37$ & 2470 & $-2,37$ \\
\hline 36 & 2760 & 2745 & $-0,54$ & 2885 & $+4,53$ & 2793 & $+1,20$ & 2690 & $-2,54$ \\
\hline 37 & 2970 & 2930 & $-1,35$ & 3100 & $+4,38$ & 2986 & $+0,54$ & 2890 & $-2,69$ \\
\hline 38 & 3160 & 3080 & $-2,53$ & 3290 & $+4,11$ & 3159 & $-0,03$ & 3070 & $-2,85$ \\
\hline 39 & 3340 & 3200 & $-4,19$ & 3430 & $+2,69$ & 3308 & $-0,96$ & 3240 & $-2,99$ \\
\hline 40 & 3500 & 3290 & $-6,00$ & 3530 & $+0,86$ & 3431 & $-1,97$ & 3380 & $-3,43$ \\
\hline 41 & 3640 & 3330 & $-8,52$ & 3615 & $-0,69$ & 3525 & $-3,16$ & 3510 & $-3,57$ \\
\hline 42 & 3750 & 3310 & $-11,73$ & 3685 & $-1,73$ & 3603 & $-3,92$ & 3620 & $-3,47$ \\
\hline 43 & 3830 & n.d. & - & n.d. & - & n.d. & - & n.d. & - \\
\hline
\end{tabular}

Note: n.d. - no data 
The study found that received standardized median (50th centile) of birth weight of newborn boys in the northwestern regions of Ukraine was somewhat different from those in other studies. The focus of differences in most cases was diverse in nature: for example, at 33 weeks of gestation median body weight according to our research was $2110 \mathrm{~g}$, according to American authors - $1970 \mathrm{~g}$, which was on average $6.64 \%$ lower compared to our results, while according to the international standards described in the "INTERGROWTH-21st Project" median body weight at 33 weeks gestation was $1950 \mathrm{~g}$, which in turn was $7.58 \%$ lower compared to our data. The same trend was observed for gestational weeks 30 to 42 for the US data and from 33 to 42 weeks of gestation for international standards. However, according to the data from a study in Malta, all indexes were in varying degrees greater than our rates. For example, the same index at 33 weeks of gestation was $2171 \mathrm{~g}$, which in turn was $2.89 \%$ higher.

However, it is advisable to note that at gestational age of 27-29 weeks the standardized median of body weight in boys of northwestern regions of Ukraine were lower compared with the results in Denver, where the latter exceeded our results by $0,76-4,85 \%$. Then, other results were greater than ours in almost all cases, and accounted for gestational weeks 27 to 37 week $+0,54-+5,30 \%$ in the Maltese work, and for 36 to 40 weeks of gestation $-+0,86-+4.53 \%$ in a Canadian study. Overall, most of our results were recorded at 29 weeks of gestation. According to the results of our work, median weight of boys at birth was $1320 \mathrm{~g}$, whereas in the Maltese it was $1390 \mathrm{~g}$, which was greater than our results by $5.30 \%$.

It was found that at 38 weeks of gestation the standardized median body weight of boys in the northwestern regions of Ukraine and Malta were almost identical - $3160 \mathrm{~g}$ and $3159 \mathrm{~g}$, respectively. Analyzing all indicators it was observed that the discordance between our results and other authors' data was fixed at 42 weeks of gestation, according to the results of our work median body weight of newborn boys was $3750 \mathrm{~g}$, whereas according to US researchers it was $3310 \mathrm{~g}$, which was on average $11.73 \%$ lower than our results.

Similar to data on boys, the obtained standardized median (50th centile) body weight in girls was compared with the results given by other authors, as shown in table 6 .

It was found that received standardized median (50th centile) of body weight of newborn girls in the northwestern regions of Ukraine did not significantly differ from those in other studies. The focus of differences in most cases had versatile character meaning that our results were in between the values of other works.

However, it is advisable to note that at age of 27 and 28 gestational weeks the standardized median body weight of girls in the northwestern regions of Ukraine were the lowest compared to all other studies: results in Denver exceeded ours by $+6.70 \%$ and by $+3.64 \%$, respectively, while the Maltese results were higher than ours by $+1.86 \%$ and $+3.55 \%$, respectively. Overall, most of our results were recorded at gestational age of 27 weeks; according to the results of our work median body weight of newborn girls was $970 \mathrm{~g}$, whereas according to Canadian researchers it was $1035 \mathrm{~g}$, which was higher than our results by $+6.70 \%$.

Similarly, it was found that the standardized median body weight of girls in the northwestern regions of Ukraine at gestational age of 40-42 weeks were the highest compared to all other studies: the US results were by $-5.95 \%--9.07 \%$ lower than ours; Canadian $-0.15 \%-$ $-1.15 \%$; Maltese $-1.73 \%--2.25 \%$, and international standards "INTERGROWTH-21st Project“ $--1.98 \%--2.98 \%$.

At gestational age of 42 weeks, median body weight of newborn girls was $3530 \mathrm{~g}$, whereas according to American researchers it was $3210 \mathrm{~g}$, which was on $-9.07 \%$ lower than our results. 
Table 6. Standardized median (50th centile) of body weight of newborn girls in the northwestern regions of Ukraine in comparison with other studies

\begin{tabular}{|c|c|c|c|c|c|c|c|c|c|}
\hline \multirow{2}{*}{$\begin{array}{l}\text { Gestational } \\
\text { age, weeks }\end{array}$} & \multirow{2}{*}{$\frac{\text { Our study }}{\text { BW }}$} & \multicolumn{2}{|c|}{$\begin{array}{c}\text { Denver, } \\
\text { Colorado,USA, } 1961 \\
\end{array}$} & \multicolumn{2}{|c|}{$\begin{array}{c}\text { Hamilton, Ontario, } \\
\text { Canada, } 1984 \\
\end{array}$} & \multicolumn{2}{|c|}{ Malta, 2009} & \multicolumn{2}{|c|}{$\begin{array}{l}\text { INTERGROWTH-21st } \\
\text { Project, } 2014\end{array}$} \\
\hline & & BW & $\%$ & BW & $\%$ & BW & $\%$ & BW & $\%$ \\
\hline 23 & n.d. & - & - & n.d. & - & 424 & - & n.d. & - \\
\hline 24 & n.d. & 760 & - & n.d. & - & 564 & - & n.d. & - \\
\hline 25 & n.d. & 845 & - & n.d. & - & 704 & - & n.d. & - \\
\hline 26 & n.d. & 935 & - & n.d. & - & 844 & - & n.d. & - \\
\hline 27 & 970 & 1035 & $+6,70$ & n.d. & - & 988 & $+1,86$ & n.d. & - \\
\hline 28 & 1100 & 1140 & $+3,64$ & n.d. & - & 1139 & $+3,55$ & n.d. & - \\
\hline 29 & 1260 & 1255 & $-0,40$ & n.d. & - & 1299 & $+3,10$ & n.d. & - \\
\hline 30 & 1440 & 1380 & $-4,17$ & n.d. & - & 1471 & $+2,15$ & n.d. & - \\
\hline 31 & 1620 & 1515 & $-6,48$ & n.d. & - & 1654 & $+2,10$ & n.d. & - \\
\hline 32 & 1830 & 1675 & $-8,47$ & n.d. & - & 1849 & $+1,04$ & n.d. & - \\
\hline 33 & 2040 & 1875 & $-8,09$ & n.d. & - & 2052 & $+0,59$ & 1860 & $-8,82$ \\
\hline 34 & 2260 & 2155 & $-4,65$ & n.d. & - & 2260 & $+0,00$ & 2130 & $-5,75$ \\
\hline 35 & 2470 & 2410 & $-2,43$ & n.d. & - & 2468 & $-0,08$ & 2380 & $-3,64$ \\
\hline 36 & 2670 & 2630 & $-1,50$ & 2785 & $+4,31$ & 2671 & $+0,04$ & 2600 & $-2,62$ \\
\hline 37 & 2880 & 2800 & $-2,78$ & 2985 & $+3,65$ & 2862 & $-0,63$ & 2800 & $-2,78$ \\
\hline 38 & 3060 & 2940 & $-3,92$ & 3130 & $+2,29$ & 3033 & $-0,88$ & 2970 & $-2,94$ \\
\hline 39 & 3200 & 3060 & $-4,38$ & 3245 & $+1,41$ & 3180 & $-0,63$ & 3130 & $-2,19$ \\
\hline 40 & 3360 & 3160 & $-5,95$ & 3355 & $-0,15$ & 3301 & $-1,76$ & 3260 & $-2,98$ \\
\hline 41 & 3470 & 3210 & $-7,49$ & 3430 & $-1,15$ & 3392 & $-2,25$ & 3370 & $-2,88$ \\
\hline 42 & 3530 & 3210 & $-9,07$ & 3495 & $-0,99$ & 3469 & $-1,73$ & 3460 & $-1,98$ \\
\hline 43 & 3570 & n.d. & - & n.d. & - & n.d. & - & n.d. & - \\
\hline
\end{tabular}

Note: n.d. - no data

\section{CONCLUSIONS}

Based on analysis of newborn body weight in the northwestern regions of Ukraine we developed local standards of newborn weight in relation to gestational age for boys and girls.

It was established that full-term newborn boys had median body weight in the range from $2880 \mathrm{~g}$ (37 weeks) to $3530 \mathrm{~g}$ (42 weeks). However, full-term newborn girls had median body weight in the range from $2880 \mathrm{~g}$ (37 weeks) to $3530 \mathrm{~g}$ (42 weeks).

Availability of processed local standards depending on gestational age will enable neonatologists, pediatricians and researchers to clearly identify anomalies in the health of newborns in this region of Ukraine. Therefore, separation of newborns with low or high birth weight will enable operational assign of adequate and timely steps to provide them neonatal care and improve their health. 


\section{REFERENCES}

1. Rigby R A, Stasinopoulos D M. Smooth centile curves for skew and kurtotic data modelled using the Box-Cox power exponential distribution. Stat Med 2004;23:76.

2. Borghi E, de Onis M, Garza C et al. For the WHO Multicentre Growth Reference Study Group. Construction of the World Health Organization child growth standards: selection of methods for attained growth curves. Stat Med 2006;25:65.

3. Akaike H. A new look at the statistical model identification. IEEE Trans Automat Contr 1974;19:23.

4. Van Buuren S, Fredriks M. Worm plot. A simple diagnostic device for modelling growth reference curves. Stat Med 2001;20:77.

5. Royston P, Wright E M. Goodness-of-fit statistics for age-specific reference intervals. Stat Med 2000;19:62.

6. WHO Multicentre Growth Reference Study Group. WHO Child Growth Standards: Length/height-for-age, weightfor-age, weight-for-length, weight-for-height and body mass index-for-age: Methods and development. Geneva: World Health Organization; 2006.

7. Трахтенберг И. М., Тычинин В. А., Сова Р. Е. и др. Основные показатели физиологической нормы у человека. - К.: Авиценна, 2001; 58-52.

8. Lubchenco, L. O. Hansman, Ch. Dressler M. et Boyd E. Intrauterine growth as estimated from liveborn birthweight data at 24 to 42 weeks of gestation. Pediatrics 1963;32;793.

9. Blidner I. N., McClemont, S. Anderson, G. D. et Sinclair J. C. Size-at-birth standards for an urban Canadian population. Can Med Assoc J. 1984; 130(2): 133-140.

10. Zammit, V. Zammit, P. Savona-Ventura, Ch. et al. Maltese national birth weight for gestational age centile values. Malta Medical Journal, 22; (2) 2010.

11. Забор В. С. Показники фізичного розвитку новонароджених різного гестаційного віку міста Львова та Львівської області і причини його порушень: дис. канд. мед. наук: Львівський національний медичний ун-т ім. Данила Галицького. - Л., 2004.

12. Villar, J. et al. International standards for newborn weight, length, and head circumference by gestational age and sex: the Newborn Cross-Sectional Study of the INTERGROWTH-21st Project for the International Fetal and Newborn Growth Consortium for the 21st Century (INTERGROWTH-21st) Lancet, 384, 2014.

\section{Corresponding author:}

Oksana Rodych, postgraduate student

Department of Pediatrics and Neonatology

Faculty of Postgraduate Education,

Danylo Halytsky Lviv National

Medical University

e-mail: rodychoksana@gmail.com 